Pathologe 2017 · 38:260-271

DOI 10.1007/s00292-017-0280-2

Online publiziert: 27. März 2017

(c) Der/die Autor(en) 2017. Dieser Artikel ist

eine Open-Access-Publikation.

Schwerpunktherausgeberin

A.M. Müller, Bonn

CrossMark

\section{Erkrankungen im frühen \\ Kindesalter (bis zum \\ 3. Lebensjahr)}

\section{Metabolische Erkrankungen}

\section{Surfactantassoziierte Erkrankungen.}

$\mathrm{Zu}$ den „häufigeren“ metabolischen Erkrankungen im frühen Kindesalter gehören genetische Defekte im Surfactantstoffwechsel. Surfactant ist ein Glykolipid, das verantwortlich ist für die Herabsetzung der Oberflächenspannung in den Alveolen. Wird kein funktionelles Surfactant gebildet, kommt es nach der Geburt zum Kollaps der Alveolen und zur massiven eingeschränkten Oxygenierung. Die Kinder fallen durch schlechte respiratorische Werte (Apgar) auf. Dahinter können sich verschiedene Mechanismen verbergen: Mutationen in den Genen für die surfactantassoziierten Apoproteine B und C, Mutationen im Gen für das Transportprotein ABCA3, aber auch Mutationen von Genen, die für den Abbau und das Recycling verantwortlich sind (,granulocytic-macrophagocytic colony stimulating factor", GMCSF [1-5]). Während die Surfactantapoprotein-Gene mit der Synthese von Surfactant assoziiert sind, reguliert ABCA3 den Transport; physiologischerweise erfolgt der Abbau der Surfactantproteine und auch der Surfactantlipide über die Makrophagen, und dieser Prozess wird durch GMCSF gesteuert. Nach Schweregrad der Symptome kann man vorsichtig Rückschlüsse auf mögliche

Detailliertere Angaben zu den beschriebenen interstitiellen Prozessen der Lunge im Kindesalter können im Buch des Autors Pathology of Lung Disease [81] entnommen werden.

\title{
H. Popper
}

Forschungseinheit für molekulare Lungen- und Pleurapathologie, Institut für Pathologie, Medizinische Universität Graz, Graz, Österreich

\section{Interstitielle Prozesse der Lunge im Kindesalter}

Ursachen ziehen: Mutationen des Surfactantapoproteins $\mathrm{B}$ und des ABCA3 zeigen nach Geburt zumeist ausgeprägte Symptome, während Mutationen im Surfactantapoprotein-C- und im GMCSFGen zuerst weniger ausgeprägte Symptome verursachen, aber im Zeitverlauf zunehmen.

Pathologisch präsentieren sich alle diese genetischen Veränderungen mit einem diffusen interstitiellen Muster entsprechend einer Alveolarproteinose. In den Alveolen findet sich eosinophil angefärbtes dendritisches zellarmes Material, das PAS-positiv ist, im Interstitium findet sich eine diskrete Infiltration mit Lymphozyten und histiozytären Zellen (• Abb. 1a).

Die definitive Diagnose erfolgt durch Genanalyse (Sequenzierung von SFTPC-, SFTPB-, CSF2RA- und -RB-, ABCA3-Gen). Findet sich eine Alveolarproteinose im späteren Kindesalter (>7 Jahre) sollte man an Autoimmunprozesse mit der Entwicklung von Autoantikörpern gegen GMCSF-Protein denken. Die Morphologie unterscheidet sich auch deutlich von der frühkindlichen Form, indem keine oder kaum interstitielle Infiltrate vorliegen und die Akkumulation von Surfactantmaterial in den Alveolen praktisch überhaupt kein dedritisches Zellmaterial enthält.

Niemann-Pick-Syndrom. Die Ursache der sehr seltenen Beteiligung der Lunge beim Nieman-Pick-Syndrom ist eine Mutation im Gen für die SpingomyelinPhosphodiesterase 1 (SMPD1). Morphologisch findet sich eine Akkumulation von Sphingomyelin in verschiedenen Organsystemen, in der Lunge mit einer Infiltration durch Makrophagen und Histiozyten, die ein schaumiges Zytoplasma aufweisen [6]. Sphingomyelin kann histochemisch mithilfe von Sudanschwarz B demonstriert oder biochemisch nachgewiesen werden. Auch in einer bronchoalveolären Lavage (BAL) können diese Niemann-Pick-Zellen gefunden werden (• Abb. 1b).

\section{Pulmonale interstitielle Glykogenose.}

Die pulmonale interstitielle Glykogenose (PIG) ist ein angeborener Defekt beim Abbau von Glykogen. In der Folge kommt es $\mathrm{zu}$ einer Akkumulation in primitiven mesenchymalen Zellen im Interstitium der Lunge (Alveolarsepten). Diese Zellen zeigen eine typische Spindelzellmorphologie und noch keine Differenzierung weder in Makrophagen noch Histiozyten (nur Vimentin-positiv). Das Glykogen wird offensichtlich aus der Zirkulation aufgenommen, da keinerlei Speicherung in den Pneumozyten nachweisbar ist [7-9]. Die Kinder sind bereits im 1. Lebensjahr symptomatisch (Tachypnoe, Hypoxie) und zeigen interstitielle Infiltrate im CT. Kinder mit PIG können auch kongenitale Herzfehler aufweisen, dies scheint aber eher eine zufällige Koinzidenz zu sein, da die Mehrzahl der publizierten Fälle dies nicht aufweist $[10,11]$. Bei vielen Kindern mit PIG kann eine Behandlung mit Kortikoiden zur Besserung der Symptome führen.

Gaucher-Erkrankung. Bei der GaucherErkrankung ist die Lunge beim Typ 1GD in sehr seltenen Fällen mitbeteiligt. Die Symptome bestehen in Dyspnoe und Hypoxie sowie Hyperventilation. Die Ursache ist eine Infiltration des Interstitiums durch Histiozyten und undifferen- 

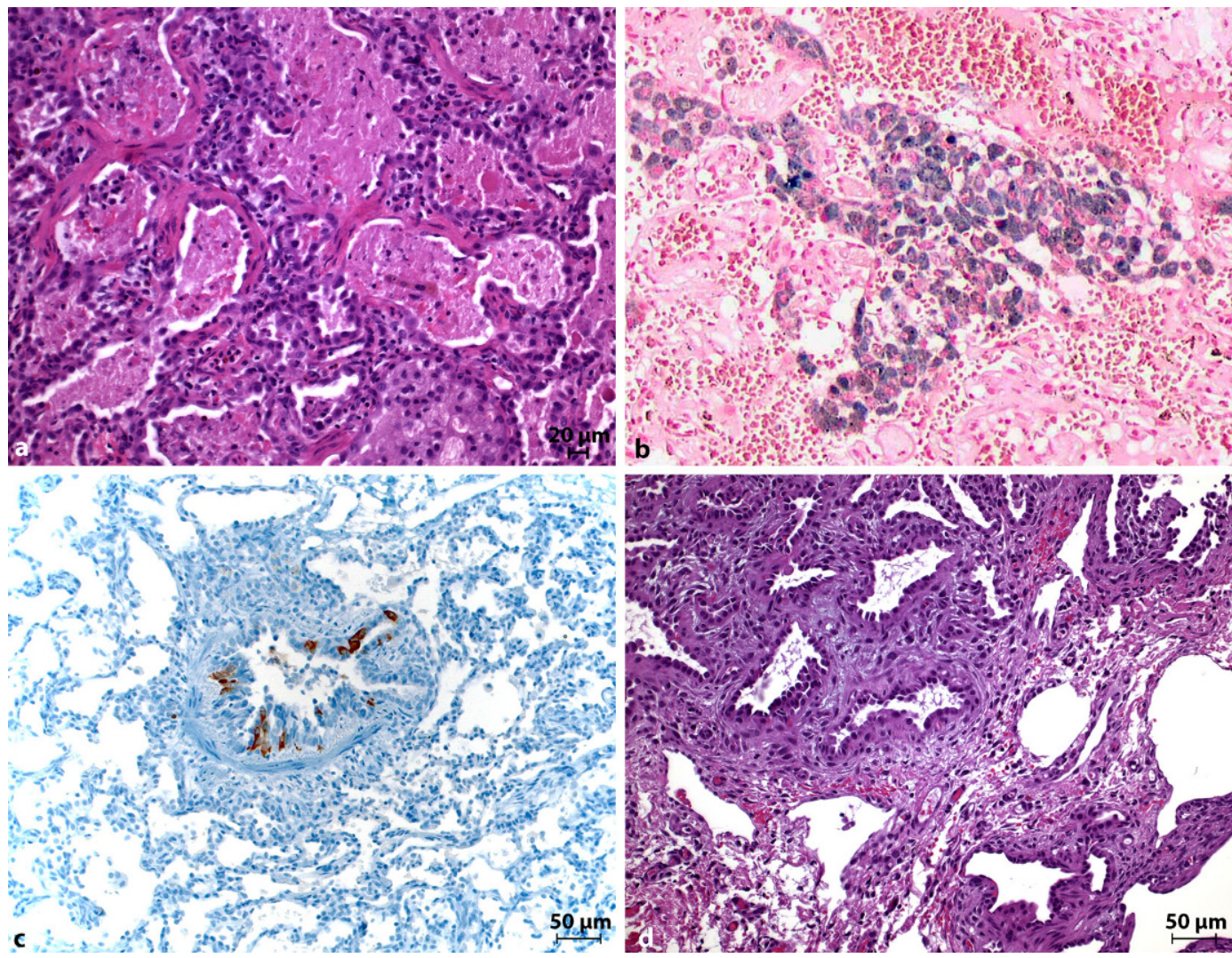

Abb. $1 \varangle$ a Interstitielle Pneumonie auf dem Boden eines Gendefekts für das Transportprotein ABCA3; charakteristisch ist die Akkumulation von eosinophilem Surfactantmaterial und Zelldetritus; offene Lungenbiopsie am 1. Tag nach Geburt. b Niemann-Pick-Speicherkrankheit bei einem Kind; Autopsiegewebe mit Ansammlungen von Makrophagen mit minimaler Eisenspeicherung und massiver $\mathrm{Li}-$ pidspeicherung (Vergrößerung 250:1). c Neuroendokrine Hyperplasie des Kindesalters, Immunhistochemie für neurales Zelladhäsionsmolekül NCAM; man erkennt hier die Vermehrung neuroendokriner Zellen in der Bronchialschleimhaut. d Bronchopulmonale Dysplasie mit diffuser Fibrose der Alveolarsepten und $\mathrm{Hy}$ perplasie der Pneumozyten Typ II

zierte Spindelzellen, die alle ein schwach eosinophil anfärbbares Zytoplasma aufweisen [12]. Im Zytoplasma dieser Zellen können Mukopolysaccharide nachgewiesen werden (idealer Weise im Gefriermaterial).

\section{Neuroendokrine Hyperplasie des Kin-} desalters. Die neuroendokrine Hyperplasie des Kindesalters (NEHI) ist auch unter dem Namen persistierende Tachypnoe des Kindesalters bekannt. Die Ätiologie ist unbekannt. Die Kinder fallen durch Tachypnoe auf. Histologisch findet sich eine Proliferation/Hyperplasie der neuroendokrinen Zellen, die man mithilfe der Immunhistochemie für neuroendokrine Marker (Synaptophysin, Chromogranin A, PGP9.5, „gastrine-releasing" Peptid/Bombesin) nachweisen kann (• Abb. 1c; [13, 14]). Ob hinter den Symptomen Tachykinine stehen, die von den neuroendokrinen Zellen abgegeben werden, ist bislang nicht untersucht worden, v. a. weil viele der Antikörper für nervale Mediatoren nicht auf formalinfixiertem Gewebe funktionieren. In den meisten Fällen kommt es innerhalb von 2 Jahren zum Verschwinden der Symptome, nur selten persistieren die Symptome bis ins spätere Kindesalter.

\section{Chronische Pneumonie des Kindesalters}

Ursprünglich umfasste diese Entität eine Reihe von Prozessen, die heute zu den metabolischen Erkrankungen (Alveolarproteinose, Glykogenose, etc.) gestellt wurden. Unter „chronic pneumonia of infancy" (CPI) wird heute nur mehr eine ätiologisch unklare chronisch interstitielle Pneumonie verstanden, d.h. es müssen bekannte Ursachen klinisch, genetisch, und pathologisch ausgeschlossen werden. Charakterisiert ist die CPI durch eine gemischte lymphohistiozytäre Infiltration in den Alveolarsepten (- Abb. 2a). Symptome sind Hypoxie und Dyspnoe bedingt durch die Verbreiterung dieser Septen und dadurch gestörtem Gasaustausch. Bei einem Teil der Fälle kann durch eine hoch dosierte Kortikoidapplikation eine Besserung, selten auch eine Heilung erzielt werden.
Hinter dem morphologischen Bild einer CPI kann sich auch das Wilson-Mikity-Syndrom verbergen. Dabei handelt es sich um eine transplazentare oder unmittelbar postpartale Infektion mit Chlamydien, respirotropen Viren oder Ureoplasma. Eine Infektion kann sogar über die Muttermilch übertragen werden [15-18].

\section{Bronchopulmonale Dysplasie}

Die bronchopulmonale Dysplasie (BPD) ist eine chronisch-entzündliche Lungenerkrankung mit Fibrose der Alveolarsepten. Ursachen sind oft Surfactantdefizienz oder Unreife der Pneumozyten Typ II. Die BPD wurde früher häufig bei Frühgeborenen mit einem Gestationsalter zwischen 26 und 30 Wochen gesehen. In dieser Zeitspanne findet noch keine Surfactantsynthese statt $[19,20]$. Mit den mittlerweile standardmäßigen Therapien von der Gabe von synthetischem Surfactant bis hin zur Gabe von hoch dosiertem Kortikoid, das eine vorzeitige Synthese von Surfaktant im Fetus induziert, ist diese Form der BPD bei uns weitgehend verschwunden. Trotzdem wird die BPD sehr 
selten diagnostiziert. Die Ursachen haben sich geändert, finden sich jetzt zumeist in Störungen der Surfactanthomöostase, Mutationen in den Surfactant-Genen bzw. in der Regulierung von Surfactantsynthese und -abbau [21-25]. Morphologisch beginnt die BPD mit einem diffusen Alveolarschaden (DAD) mit hyalinen Membranen, auf den eine Reparatur mit Fibrose der Alveolarsepten folgt (- Abb. 1d). Früher haben Sauerstoffgaben und Beatmung diesen fibrosierenden Prozess stark beschleunigt. Dies ist heute mit wesentlich besseren Methoden der Ventilation nicht mehr der Fall. Statt der diffusen Fibrose sieht man heute eher eine organisierende Pneumonie. Es kommt aber immer noch zu sekundären Infektionen, die u. U. letal verlaufen können.

\section{Zystische Fibrose}

Die zystische Fibrose (CF) wird durch einen Gendefekt im Cystic-fibrosistransmembrane-conductance-regulatorGen (CFTR) verursacht. Dieser Zellmembranrezeptor kontrolliert den zellulären Natrium- und Chloridtransport. Das CFTR-Gen befindet sich am Chromosom 7q31.2 und besteht aus 520.501 Nukleotiden mit mehreren Exons. Wichtig für die normale Funktion dieses Membrankanalrezeptors sind 2 Brücken im Protein an den Stellen Arg352-Asp993 und Arg347-Asp924. Verschiedene Interaktionen gewährleisten eine stabile offene Subkonduktanz [26]. Verschiedenste Mutationen existieren an verschiedensten Exons, die häufigste ist eine Out-offrame-Deletion dreier Nukleotide, was zum Verlust des Phenylalanins an Position 508 führt (DeltaF508). Daneben gibt es eine ebenfalls häufige Mutation an der Isoleucinposition 507 in Form einer Silencemutation. DeltaF508-CFTR bewirkt eine Fehlfaltung des Proteins, gefolgt von einem raschen Abbau im endoplasmatischen Retikulum [27-30]. Abhängig von einer homozygoten oder heterozygoten Mutation und auch von der Position der Mutation zeigen sich die Symptome frühzeitig im Kindesalter, und auch der Schweregrad ist davon abhängig.

Pathologe 2017· 38:260-271 DOI 10.1007/s00292-017-0280-2

○ Der/die Autor(en) 2017. Dieser Artikel ist eine Open-Access-Publikation.

\section{H. Popper}

\section{Interstitielle Prozesse der Lunge im Kindesalter}

\section{Zusammenfassung}

Interstitielle Prozesse in der kindlichen Lunge können sehr unterschiedliche Ursachen haben. Hier ist die Kenntnis des Alters wesentlich. Während in den ersten beiden Lebensjahren genetische Alterationen eine große Rolle spielen, sind ab dem Kindergartenalter Infektionen aber auch immunologische Erkrankungen häufiger. Insgesamt sind aber Lungenerkrankungen im Kindesalter sehr selten, was auch zur Folge hat, dass die Diagnose schwierig ist und oft erst spät gestellt wird. Hinzu kommt, dass bioptische Untersuchungen oftmals von den Kinderpulmologen nur sehr zögerlich in Betracht gezogen werden.

Um einen Beitrag zur Diagnostik kindlicher Lungenerkrankungen leisten zu können, sollten Pathologen spezialisiert sein in der Lungenpathologie, sollten auch eine gute Kenntnis genetischer Methoden haben und sich mit der fetalen Lungenentwicklung vertraut machen, wozu wiederum Kenntnis der genetischen Faktoren von Lungenwachstum und Differenzierung gehört. Ein enger Kontakt mit der pädiatrischen Pulmologie in Form gemeinsamer Fallbesprechungen fördert für beide Seiten die Qualität der Diagnostik. Die kindliche Lunge ist nicht ein verkleinertes Erwachsenenorgan, sondern reagiert in manchen Fällen völlig anders. In diesem Artikel beziehen wir uns hauptsächlich auf diffuse Infiltrationen wie sie in der High-resolution-CT (HRCT) als "ground glass", retikulonoduläre Infiltrationen etc. beschrieben werden. Lokalisierte interstitielle Prozesse, die manchmal tumorartig imponieren, werden nicht berücksichtigt. Malformationen werden nicht behandelt. Hingegen werden vaskuläre Fehlbildungen eingeschlossen, da sie durchweg diffuse interstitielle Infiltrationen ausweisen und daher zu den übrigen Erkrankungen auch in der Differenzialdiagnose zu berücksichtigen sind.

\section{Schlüsselwörter}

Genetische Alterationen - Infektionen . Immunologische Erkrankungen - Diffuse Infiltrationen · Vaskuläre Fehlbildungen

\section{Interstitial processes of the lungs in childhood}

\section{Abstract}

Interstitial processes in the lungs of children can be due to several underlying diseases. Knowledge of the child's age is important as genetic aberrations play a major role in diseases in the first 2 years, whereas immunological diseases are more common starting in kindergarden age. In general lung diseases are rare in children, which makes the diagnostics difficult and results in a delayed diagnosis. In addition, pediatric pulmonologists are often very reluctant to perform lung biopsies due to a lack of a specialized pathologist. In order to make a contribution to the diagnostics of pediatric pulmonary diseases, pathologists should be specialized in pulmonary pathology, have a good knowledge of genetic methods and fetal lung development, which includes the genetic factors involved in lung growth and differentiation. A close cooperation with the pediatric pulmonologist is necessary and each patient should be discussed jointly on an interstitial lung disease board to promote the quality of diagnostics. The pathologist should be aware that the developing lungs of children are not just a smaller form of adult lungs and often react very differently. In this article, we mainly focus on diffuse infiltration patterns, such as ground glass and reticulonodular infiltrations as described in high-resolution computed tomography (HRCT). Localized interstitial processes, which can sometimes be tumor-like and malformations are not dealt with; however, vascular malformations are included as these often manifest as diffuse interstitial infiltrations and must therefore be taken into consideration for the differential diagnostics.

\section{Keywords}

Genetic alterations · Infections · Immunological diseases - Diffuse infiltrations · Vascular malformations 
Betroffen sind bei der CF alle Organsysteme mit schleimsezernierenden Drüsen. Im unteren Atemtrakt sind dies die schleimproduzierenden Bronchialund Trachealdrüsen sowie die Becherzellen im Oberflächenepithel. Folge ist ein dicker zäher Schleim, der zu Verlegung der Atemwege (Obstruktion) führt. Daraus resultieren Bronchiektasen und in weiterer Folge kommt es zu einer chronischen Kolonisation mit Bakterien und rezidivierenden Infekten (Bronchitis und Bronchopneumonie, - Abb. 2b [27, 31-33]).

CF war eine der ersten Erkrankungen, bei der ein Gentransfer durchgeführt wurde. Dies führte anfangs zu guten Erfolgen (Mitte der 1970er Jahre), aber leider entwickelten die Patienten Autoantikörper gegen den Vektor, in dem das Gen inseriert wurde (Adenovirus). Damit wurde diese Therapie für mehrere Jahrzehnte verlassen. Neue Versuche mit modifizierten Adenovirus- und Lentivirusvektoren und auch Lipofectaminen haben mittlerweile neue Hoffnung für eine Gentransfertherapie erzeugt [34].

\section{Aspiration}

Die nächtliche unbemerkte Aspiration („nocturnal silent aspiration“) ist im Säuglingsalter relativ häufig. Ursache ist eine Schwäche des Sphinktermuskels am gastroösophagealen Übergang. Betroffen sind bevorzugt gestillte Säuglinge. Es kommt zur Regurgitation von milchhal- tigem Speisebrei und Aspiration in die Atemwege. Da dieser Magensaft weniger sauer und außerdem durch Milchbestandteile gepuffert ist, sind die Symptome weniger schwer, verglichen mit dem bevorzugt im Erwachsenenalter auftretendem Magensaftaspirationssyndrom (Mendelson-Syndrom [35]) Morphologisch kommt es zu einer makrophagendominierten Aspirationspneumonie mit sehr herdförmigen Verschattungen in den radiologischen Bildern. Das Bild erinnert an eine desquamative interstitielle Pneumonie. Die Makrophagen zeigen typisch das Bild von Lipophagen bedingt durch die Fettsubstanzen im aspirierten Material. Die Diagnose kann in der BAL gestellt werden: Lipophagen sind in der BAL in $>10 \%$ aller Makrophagen anzutreffen und können durch eine Ölrotfärbung sichtbar gemacht werden (• Abb. 2c).

Diese Muskelschwäche verschwindet üblicherweise innerhalb der nächsten Monate, braucht also nicht therapiert werden.

\section{Alveoläre kapilläre Dysplasie}

Die alveoläre kapilläre Dysplasie ist eine tödliche Erkrankung von Neugeborenen. Bei der Geburt zeigen die Kinder keinerlei Symptome. Unmittelbar nach der Geburt kommt es zur Hypoxie und pulmonalen Hypertonie. Üblicherweise werden diese Kinder assistiert beatmet und erhalten auch Sauerstoffgaben, worauf sich die Symptome sofort bessern bzw. fast verschwinden. Sobald diese Intensivmaßnahme zurückgefahren wird, kommt es sofort zur Verschlechterung. Und das wiederholt sich jedes Mal: Mechanische Ventilation und Oxygenierung - Besserung, Rückfahren der Maßnahmen in der Intensiveinheit - sofortige Verschlechterung [36].

Histologisch findet sich eine drastische Reduktion der Kapillaren - sie können herdförmig sogar gänzlich fehlen. Größere Arterien zeigen eine geringe Wandverbreiterung, arteriovenöse Anastomosen lassen sich nachweisen. In einigen Fällen kommt noch eine Fehlanordnung der Venen als weitere Fehlbildung hinzu. In diesen Fällen verlaufen die Venen zusammen mit den Arterien in den bronchovaskulären Bündeln. In diesen Fällen sind Anastomosen zwischen Venen und Arterien besonders leicht nachzuweisen Diese Venen sind deutlich ausgeweitet (• Abb. 3a; [37]).

Als Folge wird das Blut aus den Arterien direkt in die Venen umgeleitet - das Kapillarbett wird dabei weitgehend umgangen, was die schwere Hypoxie erklärt [36, 37].

Der zugrunde liegende genetische Defekt wurde kürzlich beschrieben: Es handelt sich um Mikrodeletionen mit Frameshift, Nonsense und Stopmutationen im FOXF1-Gen. Eine weitere genetische Veränderung, die ebenfalls zu diesem Phänotyp führt, ist ein Verlust des "phosphatase and tensin homolog"

Hier steht eine Anzeige. 



Abb. $2 \Delta$ a Chronische interstitielle Pneumonie des Kindesalters (Vergrößerung 100:1). Bei diesem 6 Monate alten Jungen wurde die Diagnose mithilfe der Biopsie gestellt, nachdem bronchoalveoläre Lavage (BAL) und klinische Untersuchungen kein Ergebnis brachten. Bekannte Ursachen wie metabolische Erkrankungen wurden alle ausgeschlossen. In diesem Fall besserte sich das Bild im Laufe weiterer 6 Monate unter Kortikoidstoßtherapie (HEFärbung). b Zystische Fibrose mit massiver Ausweitung der Luftwege, die mit Detritus, Schleim sowie massenhaft Granulozyten angefüllt sind; man beachte das weitgehend normale, lediglich etwas komprimierte periphere Lungengewebe (HE-Färbung). c Stille nächtliche Aspiration bei einem Säugling; bronchoalveoläre Lavage mit fetthaltigen Makrophagen (Ölrotfärbung, nativ)

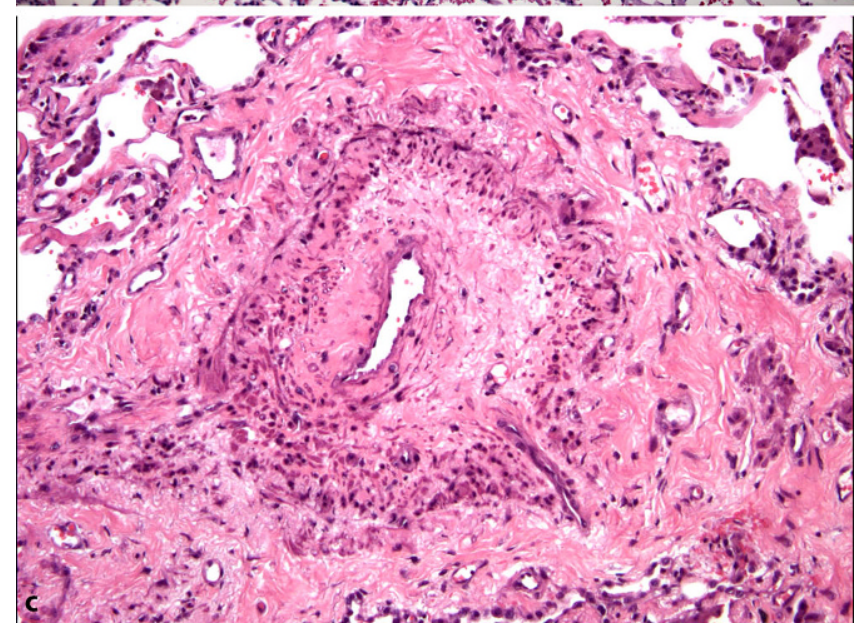

Abb. $3 \Delta$ a Alveoläre kapilläre Dysplasie mit Verlagerung der Venen; man erkennt, dass die Venen mit den Arterien gemeinsam im bronchovaskulären Bündel verlaufen und mit diesen auch Anastomosen ausbilden; weiter fällt auf, dass es kaum Kapillaren im peripheren Lungengewebe gibt. b Hereditäre hämorrhagische Teleangiektasie (Rendue-Osler-Erkrankung) mit angiomatösen Konvoluten, die sich von links oben nach rechts unten durchziehen. c Venookklusive Erkrankung bei einem 4jährigen Kind mit komplexer Malformation des Herzens; die Venen in den interlobulären Septen sind massiv verengt und fibrosiert (Vergrößerung 100:1) 

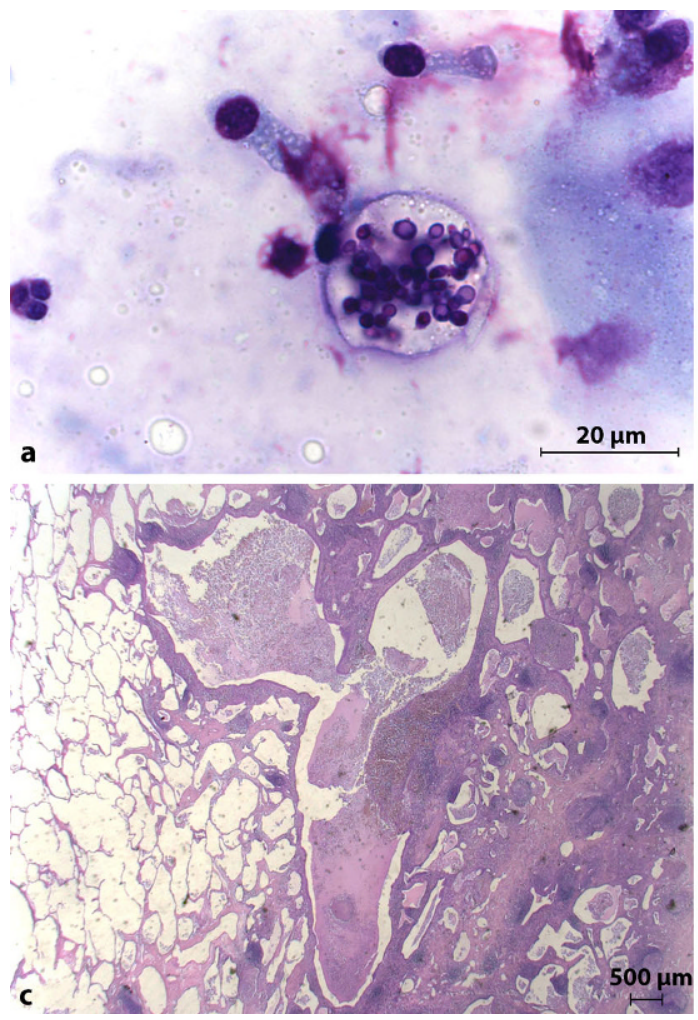

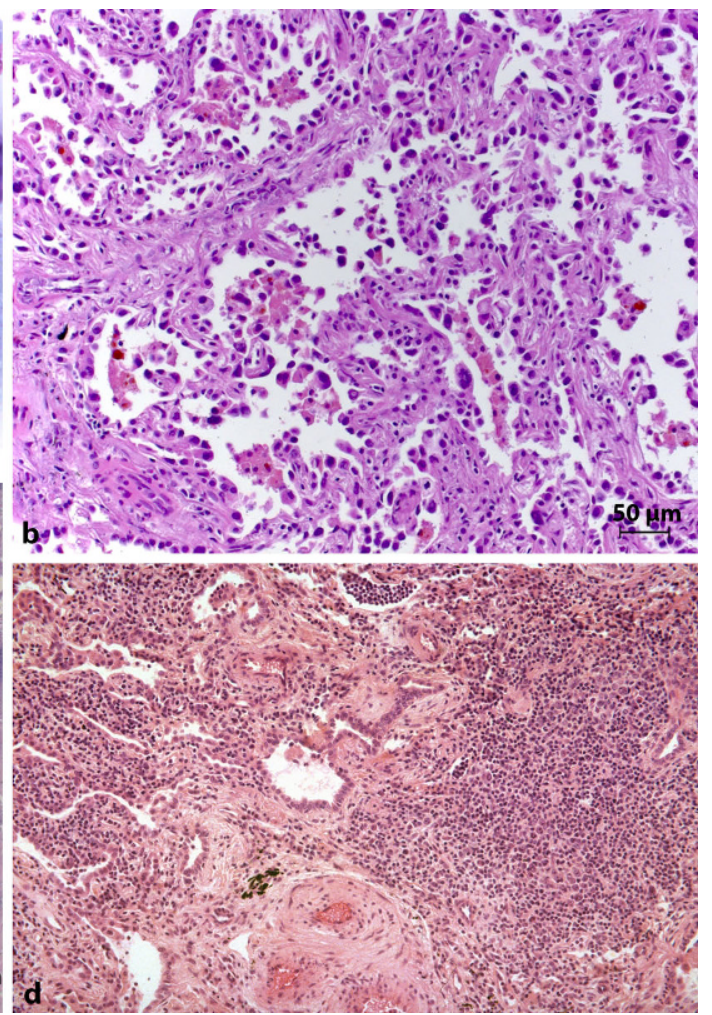

Abb. $4<$ a Kryptokokkuszyste in der bronchoalveolären Lavage (BAL) bei einem Kind nach Leukämietherapie und Knochenmarktransplantation. b Nichtspezifische interstitielle Pneumonie (NSIP) bei einem Jugendlichen im Rahmen einer Hypersensitivitätspneumonie. c Lymphozytische Pneumonie bei einem Kind mit T-Zell-Defekt (Vergrößerung 100:1).d Follikuläre Bronchiolitis bei einem Kind nach rezidivierender Virusinfektion
(PTEN) in mesodermalen Zellen, was zu einer Hemmung der Proliferation der Angioblasten führt. Es gibt auch eine Beziehung beider Mutationen zueinander. Wahrscheinlicher ist, dass nicht ein einzelner Gendefekt die Erkrankung verursacht, sondern mehrere, welche die Kommunikation zwischen den Zellen, die für die korrekte Entwicklung und Anordnung der peripheren pulmonalen Gefäße verantwortlich sind, stören. In einem Fallbericht wurde bei dieser Erkrankung auch einmal eine Trisomie 21 gefunden, zusätzlich zu Herzmissbildungen. Ob dies nur eine Koinzidenz darstellt, kann derzeit nicht beantwortet werden [38-44].

\section{Diffuse und lokalisierte AV- Anastomosen}

Primäre physiologische Anastomosen existieren während der fetalen Periode zwischen Pulmonalarterien und Bronchialvenen sowie auch pulmonalen Venen. In dieser Periode wird ein großer Teil des späteren funktionalen Kreislaufs nicht gebraucht (Gasaustausch), die Zirkulation ist wesentlich auf Ernährung für Wachstum und Entwicklung ausgerich- tet. In wieweit fetale Anastomosen im späteren Leben wieder eröffnet werden können, ist derzeit nicht geklärt. AVAnastomosen können prinzipiell in verschiedenen Lebensaltern vorkommen und präsentieren sich zumeist mit alveolärer Hämorrhagie sowie pulmonaler Hypertonie.

Diffuse AV-Anastomosen bei der Rendue-Osler-Erkrankung kommen in frühem Lebensalter vor. Je nach Befallsmuster werden die Kinder entweder schon vor dem 3. Lebensjahr oder erst danach symptomatisch. Die Erkrankung ist autosomal dominant mit vaskulären Malformationen. Die Gefäße weisen dünnwandige schlecht ausgebildete Blutgefäßkonvolute auf (hereditäre hämorrhagische Teleangiektasie) und diffuse AV-Anastomosen (• Abb. 3b). Zumeist sind Dünn- und Dickdarm betroffen, die Lunge ist selten involviert oder sogar alleiniger Sitz [45]. Klinisch kann die Erkrankung vermutet werden, wenn ein gestörter venöser ungleichzeitiger Blutrückfluss ins Herz mithilfe eines Tracers nachgewiesen wird. Die betroffenen Lungenlappen zeigen einen rascheren Rückfluss durch das Shunten über die Anastomosen verglichen mit einem normalen Lungenlappen. Die Behandlung ist immer noch eher experimentell, wenngleich Erfolge mit Bosentan bei dieser Erkrankung erzielt wurden [46]. Mutationen im endoglinund aktivinrezeptorartigen Kinase-Gen wurden kürzlich beschrieben und könnten eventuell neue Therapieoptionen eröffnen [47].

Die venookklusive Erkrankung ist charakterisiert durch Stenosen oder Verschlüsse der pulmonalen Venen. Die Erkrankung ist oft mit pulmonaler Hypertonie und pulmonaler kapillärer Hämangiomatose assoziiert bzw. ausgelöst, ist aber selten auch isoliert zu beobachten. Bei Kindern ist diese Erkrankung zumeist bei komplexen Herzfehlbildungen zu beobachten, bei denen das wesentlichste Symptom der behinderte Abfluss des Blutes aus den Lungen vorliegt. (- Abb. 3c; [48-50]). Die Lungen erscheinen bei niedriger Vergrößerung unauffällig, erst bei stärkerer Vergrößerung fällt auf, dass die Venen in den interlobulären/ interlobären Septen entweder völlig fehlen (Narben) oder massiv eingeengt sind. Mit der Elastikafärbung kann man die Reste der Venen noch nachweisen. Die Kapillaren sind üblicherweise stark aus- 


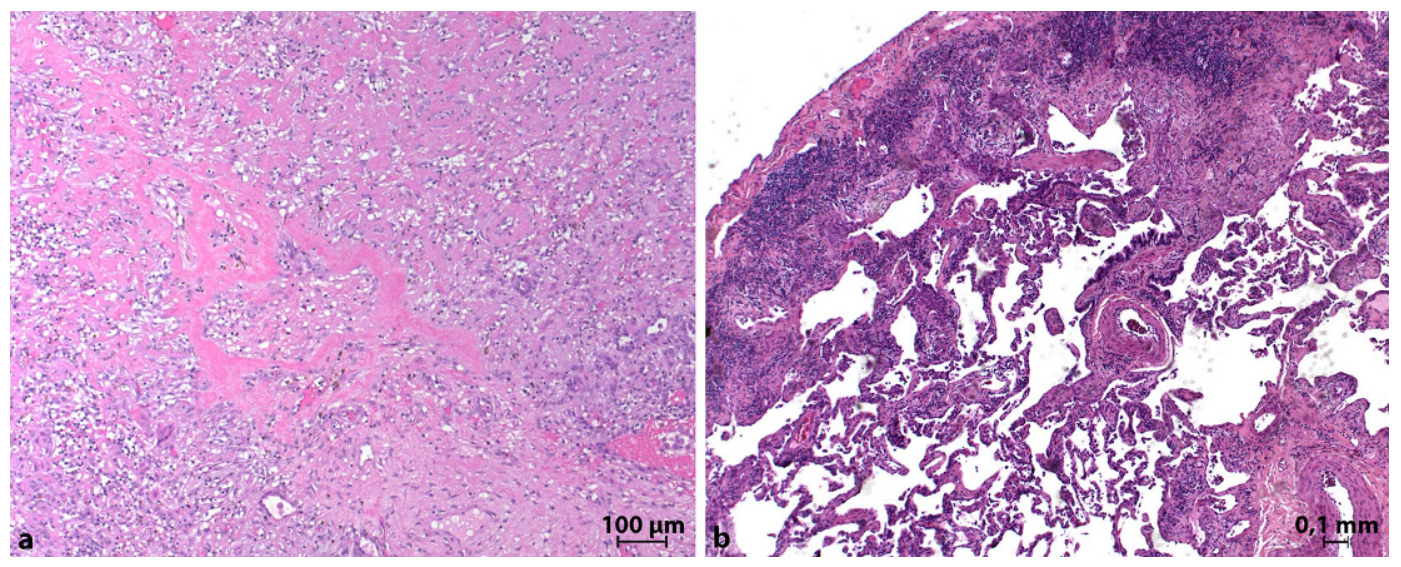

Abb. $5 \Delta$ a Systemischer Lupus erythematodes (SLE) bei einer Jugendlichen mit familiärer SLE-Anamnese; hier ist das vorherrschende Bild eine Ablagerung amyloidartiger Immunkomplexe perivaskulär wie auch interstitiell, dazu eine Thrombose mit hämorrhagischem Infarkt und an anderer Stelle auch Hämorrhagien. b Juvenile rheumatoide Arthritis bei einer 9-Jährigen; das Bild imponiert als eine lymphozytische Pneumonie kombiniert mit einem UIP-Muster (idiopathische Lungenfibrose) und Vaskulopathie

geweitet. Ein pulmonaler Hypertonus ist zumeist bei Diagnose bereits vorhanden [51]. Die Therapie bei den kindlichen Formen besteht in der Korrektur der Herzfehlbildungen, was dann auch zum weitgehenden Verschwinden der pulmonalen Symptome führt. Bei Patienten mit arterieller pulmonaler Hypertonie muss diese Erkrankung behandelt werden.

Lokalisierte AV-Anastomosen und Angiome sind hier nicht Gegenstand der Diskussion, können aber gelegentlich diffuse Hämorrhagien auslösen. Systemische Erkrankungen der Gefäßstrukturen können ebenfalls die pulmonalen Gefäße betreffen. Sowohl beim Marfan-Syndrom wie auch bei der EhlersDanlos-Erkrankung kann es zu lebensbedrohlichen Blutungen kommen bzw. kann am Anfang eine diffuse alveoläre Hämorrhagie das erste Anzeichen dafür sein. Beim Marfan-Syndrom kann die Diagnose mit einer Elastikafärbung gestellt werden, beim Ehlers-DanlosTyp IV handelt sich um einen Defekt der Prokollagensynthese. Dies resultiert in einer Wandverdünnung bei normaler Elastika. Der Nachweis erfolgt entweder biochemisch oder durch Nachweis des Gendefekts [52, 53].

Die pulmonale Sequestration wird hier nicht behandelt, da sich in den letzten Jahren zunehmend Belege gefunden haben, dass es sich dabei nicht um eine lokalisierte vaskuläre Fehlbildung handelt, sondern um eine komplexe loka- lisierte meist lappenbasierte Fehlbildung von Gefäßen und Bronchialentwicklung. Eine bronchiale Atresie und auch kongenitale pulmonale adenoidzystische Malformationen sind häufig vorhanden [54] Abnorme Venenabflüsse in den rechten Vorhof oder die V. cava inferior charakterisieren das Scimitar-Syndrom, das hier aber weil lokalisiert ebenfalls nicht behandelt wird.

\section{Erkrankungen im späteren Kindesalter}

In diesem Alter sind Infektionen häufig, besonders mit Beginn des Kindergartenalters. Pneumonien oftmals auf Basis einer viralen Infektion werden aber sehr selten pathologisch untersucht. Am ehesten sieht man Pneumonien bei Kindern mit Leukämien nach Therapie und Knochenmarktransplantation. Da stehen dann Pilzinfektionen an erster Stelle. Diagnostisch hat sich in diesen Fällen neben einer Biopsie auch die BAL etabliert, die rasch zum Nachweis des Erregers führt (๑Abb.4a).

Granulomatöse Pneumonien sind bei uns selten, sind höchstens als Tuberkulose bei Kindern nachzuweisen, wo in der engsten Verwandtschaft ein Patient mit offener Tuberkulose ein Kind ansteckt. In Entwicklungsländern ist dies aber eine häufige und nicht selten tödliche Erkrankung. Die Sarkoidose kommt nach dem 5. Lebensjahr vor, ist aber sehr selten und unterscheidet sich morphologisch nicht von Formen im Erwachsenenalter.

\section{Familiäre idiopathische Lungenfibro-}

se. Fibrosierende Pneumonien sind im Kindesalter sehr selten, kommen aber im Rahmen der familiären idiopathischen Lungenfibrose (FIPF) vor. Die Morphologie der FIPF ist heterogener als die IPF beim Erwachsenen. Jugendliche unter 15 Jahren (frühesten ab 9 Jahren) präsentieren sich vorwiegend mit einem Nichtspezifischen-interstitiellen-Pneumonie(NSIP)-Muster, während postpubertär oftmals das UIP-Muster (idiopathische Lungenfibrose) vorliegt. Im Gegensatz zu den Erwachsenen kommen bei Jugendlichen mit FIPF dichte entzündliche und sogar Lymphozytenaggregate vor, weiter die unklassifizierbare Fibrose und Muskelproliferationen. In weniger als $50 \%$ findet sich eine UIP mit Myofibroblastenherden, zystischem Umbau peripherer Lungenläppchen, Narben und dazwischen normalen Lungenarealen [55-58]. Die Mortalitätsrate bei der familiären Form ist ebenso schlecht wie die bei den Erwachsenen, nämlich $93 \%$. Eine sporadische UIP/IPF ist bei Kindern bislang nicht gesehen worden.

\section{Nichtspezifische interstitielle Pneumo-}

nie. Die nichtspezifische interstitielle Pneumonie (NSIP) ist bei Kindern beschrieben, zumeist im Kontext mit $\mathrm{Au}$ toimmunerkrankungen. Die Prognose 


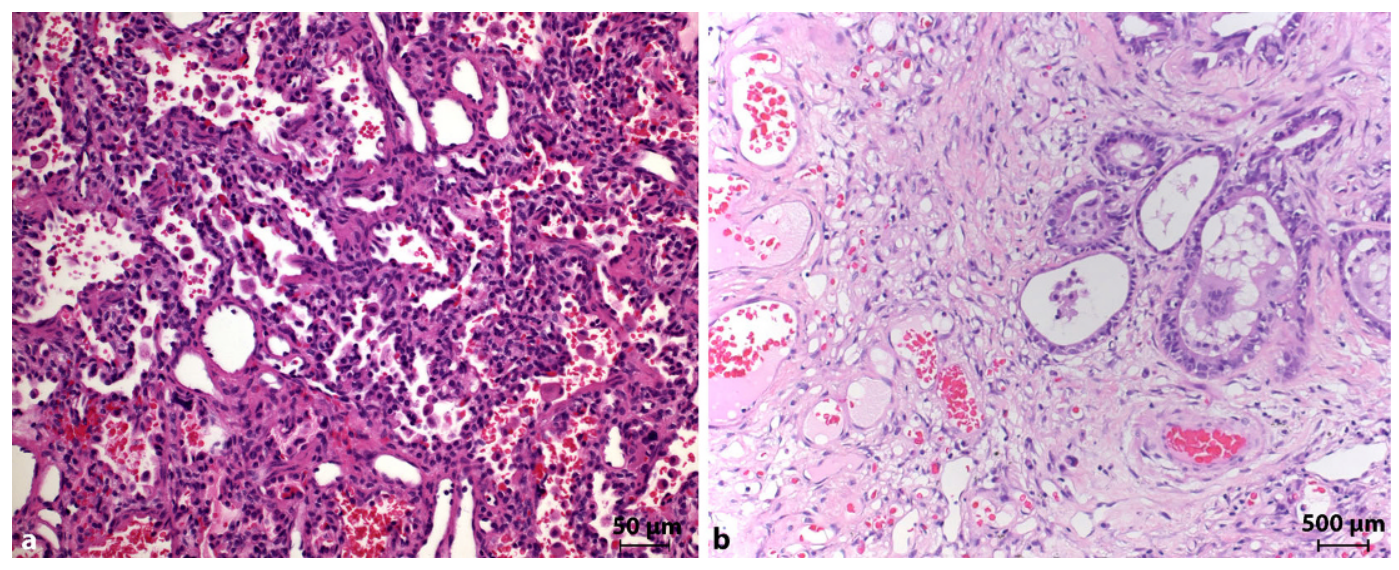

Abb. 6 ॥ a Lymphangiektasie bei einem 5 Monate alten Kind; die Ausweitung der Gefäße ist auffällig, daneben findet sich auch ein entzündliches interstitielles Infiltrat; die Natur der Gefäßveränderung wurde mithilfe der Immunhistologie für Podoplanin und VEGFR3 bestimmt. b Lymphangiomatose bei einem 15-Jährigen, die alveoläre Peripherie ist durch das lymphogene Proliferat völlig zerstört worden, zentral sind noch Reste der Atemwege vorhanden, zwischen denen allerdings ebenfalls bereits diese Proliferation sichtbar ist

ist meistens sehr schlecht, und in der Therapie kommt eine hoch dosierte Kortikoidtherapie zum Einsatz. Dies bringt das Risiko einer dadurch begünstigten Infektion mit sich, was letztlich ein Faktor für die schlechte Prognose ist. Die Morphologie ist wie bei Erwachsenen charakterisiert durch:

- erhaltene Lungenarchitektur mit Alveolarsepten, interlobulären Septen, primären und sekundären Läppchen,

- diffusen entzündlichen Infiltraten aus Lymphozyten, Makrophagen und Histiozyten sowie wenigen Plasmazellen,

- wenn vorhanden Fibrosierung der Septen ohne Zerstörung der Architektur, die Fibrose diffus, nicht herdförmig (• Abb. 4b).

Granulome können vorkommen, besonders bei der Hypersensitivitätspneumonie/EAA, sollten aber bei der idiopathischen NSIP fehlen, wie auch die Hyperplasie des bronchusassoziierten lymphoiden Systems (BALT [59, 60]).

\section{Desquamative interstitielle Pneumo-} nie. Die desquamative interstitielle Pneumonie (DIP) wurde ebenfalls bei Kindern beschrieben. Während bei Erwachsenen die Erkrankung nahezu ausschließlich durch exzessives Zigarettenrauchen ausgelöst wird, geschieht dies im Kindes-/ Jugendalter eher durch inhalative Noxen [61]. Es darf aber nicht übersehen werden, dass in einigen Ländern der industrialisierten Welt und üblicherweise in Entwicklungsländern das Zigarettenrauchen besonders bei Jugendlichen zunimmt - Österreich ist hier ein negatives Beispiel. Morphologisch ist die DIP charakterisiert durch eine dichte, fast tumorartige Infiltration der Alveolen durch Makrophagen. Dadurch sind die Alveolarsepten oft nicht mehr $\mathrm{zu}$ erkennen. Bei Rauchern enthalten die Makrophagen typisches schmutzigbräunlich-gelbes Pigment, ganz fein granulär, das Phagolysosomen entspricht, die mit Abfallprodukten des Tabakrauchs angefüllt sind.

\section{Lymphozytische interstitielle Pneumo-}

nie. Die lymphozytische interstitielle Pneumonie (LIP) ist bei Kindern ab dem Schulalter nicht selten. Sie ist charakterisiert durch eine diffuse Infiltration der peripheren Lungen durch kleine Lymphozyten, wobei auch Lymphozytenaggregate und Lymphfollikel ausgebildet werden (BALT-Hyperplasie). Im Unterschied zur NSIP ist das Infiltrat monomorph, d.h. die anderen Zellelemente sind selten (• Abb. 4c). Im Unterschied zum Erwachsenenalter kommen MALT-/BALT-Lymphome (MALT Mukosa-assoziiertes lymphatisches Gewebe) in diesem Alter kaum vor. In der Ätiologie findet man juvenile rheumatoide Arthritis, SjögrenSyndrom, Hypersensitivitätspneumo-
nie/EAA, und nicht zu vergessen HIVInfektionen [62, 63]. In seltenen Fällen liegt auch ein Immundefekt vor (s. unten).

\section{Follikuläre Bronchiolitis}

Die follikuläre Bronchiolitis (FB) erkennt man an einer Hyperplasie des BALTSystem und einer lymphozytären Infiltration der Mukosa der Bronchiolen. Die Diagnose ist eine Ausschlussdiagnose, d. h. andere Formen von Bronchiolitiden, bei denen die FB zusätzlich vorkommen kann, müssen ausgeschlossen werden.

Im ätiologischen Spektrum finden sich rezidivierende Viruserkrankungen, verschiedene Formen von Immunzelldefekten, hier besonders Defekte der T- und NK-Zellen, und auch idiopathische Formen sind beschrieben worden. Autoimmunerkrankungen können sich auch in dieser Form manifestieren [64, 65]. Die Lymphozyten sind polyklonal, je nach Ätiologie können auch B-Lymphozyten das Bild beherrschen. Die hyperplastischen Lymphfollikel komprimieren oft die Bronchiolen und führen so $\mathrm{zu}$ obstruktiven Bildern und damit oft zu sekundären Infekten. Wenn die FB zusammen mit LIP vorkommt und eventuell noch Epitheloidzellgranulome nachzuweisen sind, ist die Hypersensitivitätspneumonie/EAA die wahrscheinlichste Ursache. Dabei sind die Granulome in transbronchialen Biopsien aber 
meist nicht enthalten, da sie peripher und konzentriert subpleural vorkommen.

Prognostisch ist die FB bei viralen Infekten am besten, während die idiopathischen Formen eine schlechte Prognose aufweisen (๑Abb. 4d).

\section{Autoimmunerkrankungen}

Diese kommen ab dem Schulalter vor. Nicht alle Erkrankungen sind gleich häufig vertreten. Die juvenile rheumatoide Arthritis und der systemische Lupus erythematodes (SLE) gehören zu den am ehesten anzutreffenden Erkrankungen, während das Sjögren-Syndrom sehr selten ist. Andere Autoimmunerkrankungen oder Kollagenosen sind sehr selten - hier finden sich zumeist nur einzelne Fallberichte in der Literatur. Wir wollen uns daher nur diese 3 Entitäten näher ansehen.

\section{Systemischer Lupus erythematodes.}

Der systemische Lupus erythematodes (SLE) ist eine systemische Erkrankung, die durchaus auch die Lunge involviert. Das morphologische Spektrum zeigt eine breite Variabilität: Hämorrhagische Pneumonie, hämorrhagische Infarkte, diffuse Alveolenzerstörung (DAD), organisierende Pneumonie, Amyloidablagerungen bis hin zum Amyloidom können alle vorkommen, entweder isoliert oder auch in Kombination [64, 66, 67]. Die Ursache für diese Variationen liegt in der Erkrankung selbst. Im Zuge der intravasalen Neutrophilenzerstörung werden toxische Enzyme freigesetzt, die zu Endothelläsionen führen. Je nach Schwere kommt es zum Übertritt von Proteinen, darunter auch Immunkomplexen in die Alveolen (DAD) oder zur Hämorrhagie. In späteren Stadien (Resolution) werden die Schäden repariert - organisierende Pneumonie. Die intravaskuläre Entzündung involviert auch das Gerinnungssystem - Thrombose und Infarkt sind die Folgen. Die Ablagerung von amyloidartigem Material ist oft eine Folge von Ablagerungen von Immunkomplexen, aber auch echtes Amyloid kann gefunden werden, bestehend aus Transthyretin, $\beta 2$-Mikroglobulin und anderen Komponenten. Üblicherweise ist die Pleura beim SLE und auch den anderen Kollagenosen mitbetroffen. Gelegentlich kann in den Entzündungsinfiltraten auch das LEPhänomen nachgewiesen werden. Eine lymphozytäre Infiltration ist beim SLE eher selten im Gegensatz zur rheumatoiden Arthritis. Sklerose und Obstruktion der pulmonalen Gefäße kommen beim SLE aber auch bei den anderen Kollagenosen vor und sind die Ursache für den pulmonalen Hypertonus ( $\mathbb{0}$ Abb. 5a).

Juvenile rheumatoide Arthritis. Auch die juvenile rheumatoide Arthritis (jrhA) kann in verschiedenen morphologischen Mustern auftreten: Klassische Rheumaknoten/Granulome, LIP, NSIP, Amyloidose [68, 69]. Bei der granulomatösen Form mit Histiozyten in palisadenförmiger Anordnung um eine zentrale "Nekrose“ muss wie immer primär eine Infektion ausgeschlossen werden. Allerdings finden sich bei der jrhA innerhalb dieser „Nekrosen“ Reste zerstörter Kollagenfasern, die man durch einfache Polarisation nachweisen kann. Auch gibt es nicht den Zellkerndetritus, den man von den bakteriellen Infektionen kennt. Es ist aber trotzdem anzuraten, einen Keimausschluss durchzuführen. Bei der granulomatösen Form findet sich immer eine seropositive Form der Erkrankung. Bei Präsentation mit einem LIP oder NSIP Bild ist die Diagnose nicht einfach. Hier helfen klinische Angaben, eventuell auch Befallsmuster in anderen Organen um zur Diagnose zu gelangen (• Abb. $5 \mathbf{b})$.

Sjögren-Syndrom. Das Leitbild des Sjögren-Syndroms ist eine $\mathrm{FB}$ mit oder ohne LIP, wobei ein wichtiger Hinweis eine aggressive lymphozytäre Infiltration der Mukosa von Bronchien und Bronchiolen bis hinaus zu den Alveolen bildet. Unter aggressiver Infiltration ist $\mathrm{zu}$ verstehen, dass diese Lymphozyten das Epithel zerstören und ähnlich wie bei einem MALT-Lymphom (extranodalem Marginalzonenlymphom vom MALTTyp) lymphoepitheliale Läsionen formt [70]. Man kann dies wie beim Lymphom mithilfe der Zytokeratinimmunhistologie gut darstellen. Die Mukosa sieht wie zerfressen aus. Natürlich ist die Infiltration polyklonal. Es kann aber vorkommen, dass sich erste Herde des MALT-/BALTLymphoms nachweisen lassen mit Verlust der Polyklonalität - in etwa $40 \%$ der Fälle kann sich beim Sjögren-Syndrom ein derartiges Lymphom entwickeln, die Mechanismen werden derzeit intensiv in Tiermodellen erforscht. Im chronischen Stadium und nach schlechter Immunsuppression kann eine interstitielle fibrosierende Pneumonie vom Typ der fibrosierenden NSIP und sogar UIP folgen $[70,71]$.

\section{Erkrankungen des lymphatischen Systems}

Zum Schluss wenden wir uns noch Erkrankungen des lymphatischen Systems zu. Hier sind zwei Erkrankungen, die meist erst im pubertären Alter symptomatisch werden zu diskutieren: Lymphangiektasie und Lymphangiomatose.

Lymphangiektasie. Eine Lymphangiektasie findet sich bereits bei Kindern im Kindergartenalter. Während bei dieser Erkrankung Lymphgefäße nicht generell, sondern eher fokal betroffen sind, ist dies bei der Lymphangiomatose generalisiert, diffus und mit einer Proliferation von Lymphgefäßen verbunden. Die Abgrenzung kann aber manches Mal schwierig sein. Bei Lymphangiektasien wurden verschiedene andere Erkrankungen gefunden, so Trisomie 21 und Hydrops. Beim Hennekam-Syndrom finden sich Ektasien in den Lungen und im Darm, dazu ein kongenitales Lymphödem und Gesichtsanomalien. Bei diesen Kindern entwickelten sich ein kindlicher diffuser Alveolarschaden (DAD, früher „infant respiratory distress syndrome") und Chylothorax. Bei einigen Fällen wurde eine Mutation im FOXC2-Gen nachgewiesen, bei anderen Fällen war dies nicht nachweisbar. Aufgrund der Kombination mit anderen Anomalien ist es schwierig, gefundene Mutationen einem dieser Krankheitsbilder zuzuweisen (• Abb. 6a). Ein wichtiger klinischer Hinweis auf die Erkrankung ist der Verlust an niedermolekularen Proteinen, Elektrolyten und daraus resultierende Symptome [72-76].

Lymphangiomatose. Die Lymphangiomatose kann lokalisiert auf die Lunge 
beschränkt sein oder auch als systemische Multiorganerkrankung auftreten (Gorham-Stout-Syndrom). Symptome sind Elektrolytverlust, Verlust niedermolekularer Proteine, insbesondere Hypalbuminämie [77-80]. Daraus resultieren dann viele der klinischen Bilder. Während die systemische Form durch lytische Knochenläsionen radiologisch diagnostiziert werden kann („vanishing bone disease"), ist die lokalisierte Form schwer zu erfassen. Radiologisch findet sich ein gemischtes Muster mit "ground glass“, retikulären Verdichtungen, narbenartigen Verdichtungen, aber mit wesentlich weniger Dichtekontrast als echte Narben. Klinische Symptome können Asthma, Dyspnoe, Chylothorax und pleuropulmonale Läsionen sein.

Morphologisch finden sich endotheliale kapillarartige Proliferationen, die das periphere Lungengewebe zerstören. Oftmals finden sich Inseln aus Bronchien und einigen Bronchiolen in eine mesenchymale Matrix eingebettet. Diese Matrix enthält reichlich spindelzellige Proliferate, dazwischen finden sich Siderophagen. Pulmonale Arterien und Venen zeigen oft eine Wandverdickung. Erst bei starker Vergrößerung fallen die anastomosierenden endothelialen primitiven Schläuche auf. Durch immunhistologischen Nachweis von Podoplanin und auch Vascular-endothelial-growthfactor(VEGF)-Rezeptor 3 kann die lymphogene Natur dieser Proliferation bewiesen werden $[78,80]$. Üblicherweise ist auch die Pleura in diesen Prozess mit einbezogen (• Abb. 6b).

Bislang konnten noch keine Mutationen oder andere Abnormitäten nachgewiesen werden.

\section{Fazit für die Praxis}

- Zu den „häufigeren“ metabolischen

Erkrankungen im frühen Kindesalter gehören genetische Defekte im Surfactantstoffwechsel.

- Unter „chronic pneumonia of infancy" (CPI) wird heute nur mehr eine ätiologisch unklare chronisch interstitielle Pneumonie verstanden, charakterisiert ist die CPI durch eine gemischte lymphohistiozytäre Infiltration in den Alveolarsepten.
- Die zystische Fibrose (CF) wird durch einen Gendefekt im Cystic-fibrosis-transmembrane-conductanceregulator-Gen (CFTR) verursacht.

- AV-Anastomosen können prinzipiell in verschiedenen Lebensaltern vorkommen und präsentieren sich zumeist mit alveolärer Hämorrhagie sowie pulmonaler Hypertonie.

- Fibrosierende Pneumonien sind im Kindesalter sehr selten, kommen aber im Rahmen der familiären idiopathischen Lungenfibrose (FIPF) vor.

- Die lymphozytische interstitielle Pneumonie (LIP) ist charakterisiert durch eine diffuse Infiltration der peripheren Lungen durch kleine Lymphozyten, wobei auch Lymphozytenaggregate und Lymphfollikel ausgebildet werden (BALT-Hyperplasie).

\section{Korrespondenzadresse}

\section{Univ.-Prof. Dr. H. Popper}

Forschungseinheit für molekulare Lungenund Pleurapathologie, Institut für Pathologie, Medizinische Universität Graz Auenbruggerplatz 25, 8036 Graz, Österreich helmut.popper@medunigraz.at

Open access funding provided by Medical University of Graz.

\section{Einhaltung ethischer Richtlinien}

Interessenkonflikt. H. Popper gibt an, dass kein Interessenkonflikt besteht.

Dieser Beitrag beinhaltet keine vom Autor durchgeführten Studien an Menschen oder Tieren.

Open Access. Dieser Artikel wird unter der Creative Commons Namensnennung 4.0 International Lizenz (http://creativecommons.org/licenses/by/4.0/deed. de) veröffentlicht, welche die Nutzung, Vervielfältigung, Bearbeitung, Verbreitung und Wiedergabe in jeglichem Medium und Format erlaubt, sofern Sie den/die ursprünglichen Autor(en) und die Quelle ordnungsgemäßnennen, einen Link zur Creative Commons Lizenz beifügen und angeben, ob Änderungen vorgenommen wurden.

\section{Literatur}

1. Citti A, Peca D, Petrini S, Cutrera R, Biban P, Haass C, Boldrini R, Danhaive O (2013) Ultrastructural characterization of genetic diffuse lung diseases in infants and children: a cohort study and review. Ultrastruct Pathol 37:356-365
2. Martinez-Moczygemba M, Doan ML, Elidemir $\mathrm{O}$ Fan LL, Cheung SW, Lei JT, Moore JP, Tavana G, Lewis LR, Zhu Y, Muzny DM, Gibbs RA, Huston DP (2008) Pulmonary alveolar proteinosis caused by deletion of the GM-CSFRalpha gene in the $X$ chromosome pseudoautosomal region 1. J Exp Med 205:2711-2716

3. Bruder E, Hofmeister J, Aslanidis C, Hammer J, Bubendorf L, Schmitz G, Rufle A, Buhrer C (2007) Ultrastructural and molecular analysis in fatal neonatal interstitial pneumonia caused by a nove ABCA3 mutation. Mod Pathol 20:1009-1018

4. Latzin $P$, Tredano $M$, Wust $Y$, de Blic J, Nicolai $T$, Bewig B, Stanzel F, Kohler D, Bahuau M, Griese M (2005) Anti-GM-CSF antibodies in paediatric pulmonary alveolar proteinosis. Thorax 60:39-44

5. Tredano M, Griese M, Brasch F, Schumacher $S$, de Blic J, Marque S, Houdayer C, Elion J, Couderc R, Bahuau M (2004) Mutation of SFTPC in infantile pulmonary alveolar proteinosis with or without fibrosing lung disease. Am J Med Genet 126A:18-26

6. Guillemot N, Troadec C, de Villemeur TB, Clement A, Fauroux B (2007) Lung disease in Niemann-Pick disease. Pediatr Pulmonol 42:1207-1214

7. Deutsch GH, Young LR (2016) Lipofibroblast phenotype in pulmonary interstitial glycogenosis. Am J Respir Crit Care Med 193:694-696

8. Deutsch GH, Young LR (2009) Histologic resolution of pulmonary interstitial glycogenosis. Pediatr Dev Pathol 12:475-480

9. Canakis AM, Cutz E, Manson D, O'Brodovich H (2002) Pulmonary interstitial glycogenosis: a new variant of neonatal interstitial lung disease. Am J Respir Crit Care Med 165:1557-1565

10. Morrison AK, Patel M, Johnson SL, LeGallo R, Teague WG, Vergales B (2016) Pulmonary interstitial glycogenosis in a patient with trisomy 21. J Neonatal Perinatal Med 9:227-231

11. Alkhorayyef A, Ryerson L, Chan A, Phillipos E, Lacson A, Adatia I (2013) Pulmonary interstitial glycogenosis associated with pulmonary hypertension and hypertrophic cardiomyopathy. Pediat Cardiol 34:462-466

12. Miller A, Brown LK, Pastores GM, Desnick RJ (2003) Pulmonary involvement in type 1 Gaucher disease: functional and exercise findings in patients with and without clinical interstitial lung disease. Clin Genet 63:368-376

13. Popler J, Gower WA, Mogayzel PJ Jr., Nogee LM Langston C, Wilson AC, Hay TC, Deterding RR (2010) Familial neuroendocrine cell hyperplasia of infancy. Pediatr Pulmonol 45:749-755

14. Deterding RR, Pye C, Fan LL, Langston C (2005) Persistent tachypnea of infancy is associated with neuroendocrine cell hyperplasia.PediatrPulmonol 40:157-165

15. Wilson MG, Mikity VG (1960) A new form of respiratory disease in premature infants. AMA J Dis Child 99:489-499

16. Oetgen WJ (1979) Chlamydial pneumonia of infancy vs Wilson-Mikity syndrome. Pediatrics 64:119-120

17. Numazaki K, Chiba S, Kogawa K, Umetsu M, Motoya H, Nakao T (1986) Chronic respiratory disease in premature infants caused by Chlamydia trachomatis. J Clin Pathol 39:84-88

18. Reiterer F, Dornbusch HJ, Urlesberger B, Reittner $P$, Fotter R, Zach M, Popper H, Muller W (1999) Cytomegalovirus associated neonatal pneumonia and Wilson-Mikity syndrome: a causal relationship? Eur Respir J 13:460-462 
19. Parton LA, Strassberg SS, Qian D, Galvin-Parton PA, Cristea IA (2006) The genetic basis for bronchopulmonary dysplasia. Front Biosci 11:1854-1860

20. Chess PR, D'Angio CT, Pryhuber GS, Maniscalco WM (2006) Pathogenesis of bronchopulmonary dysplasia. Semin Perinatol 30:171-178

21. Zhang S, Zhang $X$, Li Q, Kong X, Zhang $Y$, Wei $X$, Song J, Feng Z (2015) Surfactant protein B gene polymorphisms is associated with risk of bronchopulmonary dysplasia in Chinese Han population. Int J Clin Exp Pathol 8:2971-2978

22. Somaschini M, Castiglioni E, Presi S, Volonteri C, Ferrari M, Carrera P (2012) Genetic susceptibility to neonatal lung diseases. Acta Biomed 83(Suppl 1):10-14

23. Poggi C, Giusti B, Vestri A, Pasquini E, Abbate R, Dani C (2012) Genetic polymorphisms of antioxidant enzymes in preterm infants. J Matern Fetal Neonatal Med 25(Suppl 4):131-134

24. Somaschini M, Castiglioni E, Volonteri C, Cursi M, Ferrari M, Carrera P (2012) Genetic predisposing factors to bronchopulmonary dysplasia: preliminary data from a multicentre study. J Matern Fetal Neonatal Med 25(Suppl4):127-130

25. Ryckman KK, Dagle JM, Kelsey K, Momany AM, Murray JC (2012) Geneticassociations of surfactant protein $\mathrm{D}$ and angiotensin-converting enzyme with lung disease in preterm neonates. J Perinato 32:349-355

26. Cui G, Freeman CS, Knotts T, Prince CZ, Kuang C, McCarty NA (2013) Two salt bridges differentially contribute to the maintenance of cystic fibrosis transmembrane conductance regulator (CFTR) channel function. JBiol Chem 288:20758-20767

27. Bali V, Lazrak A, Guroji P, Matalon S, Bebok Z (2016) Mechanistic approaches to improve correction of the most common disease-causing mutation in cystic fibrosis. PLOSONE 11:e0155882

28. Furlan LL, Marson FA, Ribeiro JD, Bertuzzo CS, Salomao Junior JB, Souza DR (2016) IL8 gene as modifier of cystic fibrosis: unraveling the factors which influence clinical variability. Hum Genet 135:881. doi:10.1007/s00439-016-1684-4

29. Lazrak A, Fu L, Bali V, Bartoszewski R, Rab A, Havasi V, Keiles S, Kappes J, Kumar R, Lefkowitz E, Sorscher EJ, Matalon S, Collawn JF, Bebok Z (2013) The silent codon change I507-ATC->ATT contributes to the severity of the DeltaF508 CFTR channel dysfunction. FASEB J 27:4630. doi:10.1096/fj.13227330

30. Prach L, Koepke R, Kharrazi M, Keiles S, Salinas DB, Reyes MC, Pian M, Opsimos H, Otsuka KN, HardyKA, Milla CE, Zirbes JM, Chipps B, O'Bra S, Saeed MM, Sudhakar R, Lehto S, Nielson D, Shay GF, Seastrand M, Jhawar S, Nickerson B, Landon C, Thompson A, Nussbaum E, Chin T, WojtczakH (2013) Novel CFTR variants identified during the first 3 years of cystic fibrosis newborn screening in California. J Mol Diagn 15:710-722

31. Ralhan A, Laval J, Lelis F, Ballbach M, Grund C, Hector A, Hartl D (2016) Current concepts and controversies in innate immunity of cystic fibrosis lung disease. J Innate Immun 8:531. doi:10.1159/ 000446840

32. Adler FR, Liou TG (2016) The dynamics of disease progression in cystic fibrosis. PLOS ONE 11:e0156752

33. Stanke F, van Barneveld A, Hedtfeld S, Wolfl S, Becker T, Tummler B (2013) The CF-modifying gene EHF promotes $p$.Phe508del-CFTR residual function by altering protein glycosylation and trafficking in epithelial cells. Eur J Hum Genet 22:660. doi:10. 1038/ejhg.2013.209
34. Griesenbach U, Alton EW (2013) Moving forward: cystic fibrosis gene therapy. Hum Mol Genet 22:R52-R58

35. Raghu G, Meyer KC (2012) Silent gastro-oesophageal reflux and microaspiration in IPF: mounting evidence for anti-reflux therapy? Eur Respir J 39:242-245

36. Gutierrez C, Rodriguez A, Palenzuela S, Forteza C, Rossello JL (2000) Congenital misalignment of pulmonary veins with alveolar capillary dysplasia causing persistent neonatal pulmonary hypertension: report of two affected siblings. Pediatr Dev Pathol 3:271-276

37. Pucci A, Zanini C, Ferrero F, Arisio R, Valori A, Abbruzzese P, Forni M (2003) Misalignment of lung vessels: diagnostic role of conventional histology and immunohistochemistry. Virchows Arch 442:597-600

38. Stankiewicz P, Sen P, Bhatt SS, Storer M et al (2009) Genomic and genic deletions of the FOX gene cluster on 16q24.1 and inactivating mutations of FOXF1 cause alveolar capillary dysplasia and other malformations. Am JHum Genet 84:780-791

39. Zufferey F, Martinet D, Osterheld MC, Niel-Butschi F, Giannoni E, Schmutz NB, Xia Z, Beckmann JS, Shaw-Smith C, Stankiewicz P, Langston C, Fellmann $F(2011)$ 16q24.1 microdeletion in a premature newborn: usefulness of array-based comparative genomic hybridization in persistent pulmonary hypertension of the newborn. Pediatr Crit Care Med 12:e427-e432

40. Yu S, Shao L, Kilbride H, Zwick DL (2010) Haploinsufficiencies of FOXF1 and FOXC2 genes associated with lethal alveolar capillary dysplasia and congenital heart disease. Am J Med Genet A 152A:1257-1262

41. Tiozzo C, Carraro G, Al Alam D, Baptista S, Danopoulos S, Li A, Lavarreda-Pearce M, Li C, De Langhe S, Chan B, Borok Z, Bellusci S, Minoo $P$ (2012) Mesodermal Pten inactivation leads to alveolar capillary dysplasia- like phenotype. J Clin Invest 122:3862-3872

42. Laux D, Malan V, Bajolle $F$, Boudjemline $Y$, Amiel J, Bonnet D (2013) FOX gene cluster defects in alveolar capillary dysplasia associated with congenital heart disease. Cardiol Young 23:697-704. doi:10.1017/s1047951112001904

43. Galambos C (2006) Alveolar Capillary Dysplasia in a Patient with Down's Syndrome. Pediatr Dev Pathol 9:254-255 (author reply 6)

44. Shehata BM, Abramowsky CR (2005) Alveolar capillary dysplasia in an infant with trisomy 21. Pediatr Dev Pathol 8:696-700

45. Giordano P, Nigro A, Lenato GM, Guanti G, Suppressa P, Lastella P, De Mattia D, Sabba C (2006) Screening for children from families with RenduOsler-Weber disease: from geneticist to clinician. JThromb Haemost 4:1237-1245

46. Ivy DD, Rosenzweig EB, Lemarie JC, Brand M, Rosenberg D, Barst RJ (2010) Long-term outcomes in children with pulmonary arterial hypertension treated with bosentan in real-world clinical settings. Am J Cardiol 106:1332-1338

47. Sadick H, Hage J, Goessler U, Stern-Straeter J, Riedel F, Hoermann K, Bugert P (2009) Mutation analysis of "Endoglin" and "Activin receptor-like kinase" genes in German patients with hereditary hemorrhagic telangiectasia and the value of rapid genotyping using an allelespecific PCR-technique. BMCMed Genet 10:53

48. Carrington CB, Liebow AA (1970) Pulmonary venoocclusive disease. Hum Pathol 1:322-324

49. Kim JJ,KearneyDL,GrifkaRG,McKenzieED, MottAR (2005) Pulmonary venous stenosis as an associated manifestation of left-sided obstructive lesions in an infant with partial atrioventricular canal defect. Pediatr Cardiol 26:449-451

50. Montani D, Lau EM, Dorfmuller P, Girerd B, Jais $X$, Savale L, Perros F, Nossent E, Garcia G, Parent F, Fadel E, Soubrier F, Sitbon O, Simonneau G, Humbert M (2016) Pulmonary veno-occlusive disease. Eur Respir J47:1518-1534

51. Lantuejoul S, Sheppard MN, Corrin B, Burke MM, Nicholson AG (2006) Pulmonary venoocclusive dis ease and pulmonary capillary hemangiomatosis: a clinicopathologic study of 35 cases. Am J Surg Pathol 30:850-857

52. Dinwiddie R, Sonnappa S (2005) Systemic diseases and the lung. Paediatr Respir Rev 6:181-189

53. Watanabe A, Kawabata $\mathrm{Y}$, Okada O, Tanabe $\mathrm{N}$, Kimura H, Hatamochi A, Shinkai H, Sakai N, Shimada T, Hiroshima K, Kuriyama T (2002) EhlersDanlos syndrome type IV with few extrathoracic findings: a newly recognized point mutation in the COL3A1 gene. Eur Respir J 19:195-198

54. Riedlinger WF, Vargas SO, Jennings RW, Estroff JA, Barnewolt CE, Lillehei CW, Wilson JM, Colin AA, Reid LM, Kozakewich HP (2006) Bronchial atresia is common to extralobar sequestration, intralobar sequestration, congenital cystic adenomatoid malformation, and lobar emphysema. Pediatr Dev Pathol 9:361-373

55. Lee HL, Ryu JH, Wittmer MH, Hartman TE, Lymp JF, Tazelaar HD, Limper AH (2005) Familial idiopathic pulmonary fibrosis: clinical features and outcome. Chest 127:2034-2041

56. Fernandez BA, Fox G, Bhatia R, Sala E, Noble B, Denic N, Fernandez D, Duguid N, Dohey A, Kamel F, Edwards L, Mahoney K, Stuckless S, Parfrey PS, Woods MO (2012) A Newfoundland cohort of familial and sporadicidiopathic pulmonary fibrosis patients: clinical and genetic features. Respir Res 13:64

57. Wytrychowski K, Hans-Wytrychowska A, Nowakowska B (2013) Familial idiopathic pulmonary fibrosis. Adv Exp Med Biol 788:363-367

58. Leslie KO, Cool CD, Sporn TA, Curran-Everett D, Steele MP, Brown KK, Wahidi MM, Schwartz DA (2012) Familial idiopathic interstitial pneumonia: histopathology and survival in 30 patients. Arch Pathol Lab Med 136:1366-1376

59. Kambouchner M, Levy P, Nicholson AG, Schubel K, Magois E, Feuillet S, Valeyre D, Bernaudin JF, Nunes H (2014) Prognostic relevance of histological variants in nonspecific interstitial pneumonia. Histopathology 65:549-560

60. Churg A, Sin DD, Everett D, Brown K, Cool C (2009) Pathologic patterns and survival in chronic hypersensitivity pneumonitis. Am J Surg Pathol 33:1765-1770

61. Godbert B, Wissler MP, Vignaud JM (2013) Desquamative interstitial pneumonia: an analytic review with an emphasis on aetiology. Eur Respir Rev 22:117-123

62. Cottin V, Thivolet-Bejui F, Reynaud-Gaubert $M$ Cadranel J, Delaval P, Ternamian PJ, Cordier JF (2003) Interstitial lung disease in amyopathic dermatomyositis, dermatomyositis and polymyositis. Eur Respir J 22:245-250

63. BourkeSJ, Dalphin JC, Boyd G, MCSharry C, Baldwin Cl, Calvert JE (2001) Hypersensitivity pneumonitis: current concepts. Eur Respir J Suppl 32:81s-92s

64. Tansey D, Wells AU, Colby TV, Ip S, Nikolakoupolou A, du Bois RM, Hansell DM, Nicholson AG (2004) Variations in histological patterns of interstitial pneumonia between connective tissue disorders and their relationship to prognosis. Histopathology 44:585-596 
65. Popper HH (2000) Bronchiolitis, an update. Virchows Arch 437:471-481

66. Crestani B (2005) The respiratory system in connective tissue disorders. Allergy 60:715-734

67. Torre O, Harari S (2011) Pleural and pulmonary involvement in systemic lupus erythematosus. Presse Med 40:e19-e29

68. Hakala M, Paakko P, Huhti E, Tarkka M, Sutinen S (1990) Open lung biopsy of patients with rheumatoid arthritis. Clin Rheumatol 9:452-460

69. Lee HK, Kim DS, Yoo B, Seo JB, Rho JY, Colby TV, Kitaichi M (2005) Histopathologic pattern and clinical features of rheumatoid arthritis-associated interstitial lung disease. Chest 127:2019-2027

70. Parambil JG, Myers JL, Lindell RM, Matteson EL, Ryu JH (2006) Interstitial lung disease in primary Sjogren syndrome. Chest 130:1489-1495

71. Suda T, Kaida Y, Nakamura Y, Enomoto N, Fujisawa T, Imokawa S, Hashizume H, Naito T, Hashimoto D, Takehara Y, Inui N, Nakamura H, Colby TV, Chida K (2009) Acute exacerbation of interstitial pneumonia associated with collagen vascular diseases. Respir Med 103:846-853

72. Reiterer F, Grossauer K, Pfleger A, Hausler M, Resch B, Eber E, Popper H, Urlesberger B (2015) Severe primary pulmonary lymphangiectasis in a premature infant: management and follow up to early childhood. Pediatr Int 57:166-169

73. Toyoshima M, Suzuki S, Kono M, Nakamura $Y$, Suda T (2014) Mildly progressive pulmonary lymphangiectasis diagnosed in a young adult. Am JRespir Crit Care Med 189:860-862

74. Yao LC, Testini C, Tvorogov D, Anisimov A, Vargas SO, Baluk P, Pytowski B, Claesson-Welsh L, Alitalo K, McDonald DM (2014) Pulmonary lymphangiectasia resulting from vascular endothelial growth factor-C overexpression during a critical period. Circ Res 114:806-822

75. Mele P, Sridhar S (2012) Congenital pulmonary lymphangiectasia: an unusual presentation of nonimmune hydrops in a preterm infant. Adv Neonatal Care 12:166-171

76. de Bruyn G, Casaer A, Devolder K, Van Acker G, Logghe H, Devriendt K, Cornette L (2012) Hydrops fetalis and pulmonary lymphangiectasia due to FOXC2 mutation: an autosomal dominant hereditary lymphedema syndrome with variable expression. Eur JPediatr 171:447-450

77. Bhatti MA, Ferrante JW, Gielchinsky I, Norman JC (1985) Pleuropulmonary and skeletal lymphangiomatosis with chylothorax and chylopericardium. Ann Thorac Surg 40:398-401

78. Ramani P, Shah A (1993) Lymphangiomatosis. Histologic and immunohistochemical analysis of four cases. Am J Surg Pathol 17:329-335

79. Shah AR, Dinwiddie R, Woolf D, Ramani R, Higgins JN, Matthew DJ (1992) Generalized lymphangiomatosis and chylothorax in the pediatric age group. Pediatr Pulmonol 14:126-130

80. Tazelaar HD, Kerr D, Yousem SA, Saldana MJ, Langston C, Colby TV (1993) Diffuse pulmonary lymphangiomatosis. Hum Pathol 24:1313-1322

81. Popper H (2017) Pediatric Diseases. In: Popper $\mathrm{H}$ (Hrsg) Pathology of Lung Disease. Morphology, Pathogenesis, Etiology. Springer, Berlin Heidelberg, S21-57

\section{Neuer Ansatz bei Antibiotika- therapie gegen Resistenzen}

Kieler Forschungsteam nutzt evolutionäres Prinzip zur Entwicklung nachhaltiger Behandlungsformen in der Antibiotikatherapie.

Die Arbeitsgruppe Evolutionsökologie und Genetik der Christian-Albrechts-Universität zu Kiel (CAU) konnte in einer Studie belegen, dass beim Krankheitskeim Pseudomonas aeruginosa die Evolution von Resistenz gegen bestimmte Antibiotika gleichzeitig zu einer erhöhten Empfindlichkeit gegenüber anderen Wirkstoffen führt.

Dieses Konzept der sogenannten „kollateralen Sensitivität" eröffnet neue Perspektiven in der Bekämpfung multiresistenter Krankheitserreger. Als besonders effektiv stellte sich die Kombination von Antibiotika heraus, die unterschiedliche Wirkmechanismen aufweisen - insbesondere aus den Klassen der Aminoglykoside und Penicilline. Die Untersuchung der genetischen Grundlagen dieser Resistenzbildungen zeigte, dass drei spezifische Gene des Bakteriums dafür sorgten, dass es zugleich resistent und anfällig wird. Durch den kombinierten oder abwechselnden Einsatz von Antibiotika mit wechselseitigen Sensitivitäten lassen sich die Keime potentiell in eine evolutionäre Sackgasse treiben: Sobald sie gegen das eine resistent werden, sind sie empfindlich gegen das andere und umgekehrt, fassen die Autoren die Bedeutung der vorliegenden Arbeit zusammen. Diese neuen Ergebnisse aus dem Labor machen Hoffnung. Eine gezielte Kombination der noch wirksamen Antibiotika könnte zumindest für eine Atempause im Kampf gegen die sehr problematischen Resistenzbildungen sorgen

Quelle: Universität Kiel (www.uni-kiel.de)

basierend auf: Barbosa C et al (2017) Molecular Biology and Evolution doi 10.1093/molbev/msx158
Muskuläres BICD2-Syndrom entdeckt

Eine neue seltene Muskelkrankheit haben Forscher der Ruhr-Universität Bochum (RUB) entdeckt. Ursache für die vererbbare Erkrankung ist ein Defekt im Gen $\mathrm{BICD2}$, der sich in veränderten zellulären Transportprozessen in Skelettmuskelzellen äußert. Betroffene leiden an Muskelschwäche in den Beinen, einem unsicheren Gang und der ständigen Gefahr zu stolpern. BICD2 war schon vorher als Krankheitsauslöser bekannt, allerdings nur für Krankheiten, deren Ursache im Nervensystem liegt. Die bisherigen Befunde legen nahe, dass BICD2-Defekte ein ganzes Spektrum von neuromuskulären Erkrankungen auslösen können.

\section{Transportweg beeinträchtigt}

Bei den von dem Bochumer Team beschriebenen Patienten mit muskulärer BICD2-Krankheit waren Unter- und Oberschenkelmuskulatur betroffen, aber keine relevanten Veränderungen im Nervensystem sichtbar. Physiologische Untersuchungen offenbarten, dass die Myofibrillen degeneriert waren. Zellorganellen, nämlich Mitochondrien und Golgi-Apparat, waren in Form und Größe verändert. Wie der BICD2-Gendefekt diese vielfältigen Veränderungen auslöst, soll nun in Zukunft erforscht werden. Die Forscher gehen davon aus, dass das kranke BICD2-Protein den gerichteten Transport in Muskelzellen beeinträchtigt. Soll eine Fracht innerhalb der Zelle transportiert werden, wird sie dazu in ein Membranbläschen verpackt und von einem beweglichen Motorprotein befördert. Das BICD2-Protein fungiert als Adapter zwischen der zu transportierenden Fracht und dem Motorprotein. Es bestimmt mit, welche Fracht transportiert wird und wohin, und es reguliert die Geschwindigkeit des Motorproteins.

\section{Quelle: Ruhr-Universität Bochum} (www.rub.de)

basierend auf: Neurology (2016) DOI:10.1212/WNL.0000000000003360 